\title{
LV.IL-2/B7.1-Transduced AML Blast Vaccine RFUSIN2-AML1
}

National Cancer Institute

\section{Source}

National Cancer Institute. LV.IL-2/B7.1-Transduced AML Blast Vaccine RFUSIN2-AML1. NCI Thesaurus. Code C78832.

A whole-cell cancer vaccine, containing human acute myeloid leukemic (AML) blasts that have been genetically eng ineered to express a B7.1/IIL-2 fusion protein encoded by a self-inactivating lentiviral vector (LV), with potential antineoplastic and immunomodulating activities. Upon administration, LV.IL-2/B7.1-transduced AML blast vaccine RFUSIN2-AML1 may stimulate a host cytotoxic T lymphocyte $(C T L)$ response against AML cells. The single fusion protein encoded by the LV is postsynthetically cleaved to produce biologically active membrane-anchored B7.1 and secreted IL-2 in AML blasts; combined expression of IL-2 and the co-stimulatory molecule B7.1 by AML blasts may increase stimulation of both allogeneic and autologous cytotoxic T cells. 